\title{
The Fitz Hugh-Curtis Syndrome and Hydrosalpinx: Analysis of Findings in Gynecologic Laparoscopy Procedure of Infertile Women
}

\author{
Hartanto Bayuaji ${ }^{*}$, Wiryawan Permadi ${ }^{1}$, Heda Melinda Nazaruddin Nataprawira² \\ ${ }^{1}$ Department of Obstetrics \& Gynecology, Faculty of Medicine, Universitas Padjadjaran/Hasan Sadikin Hospital, Bandung, \\ Indonesia \\ ${ }^{2}$ Department of Child Health, Faculty of Medicine, Universitas Padjadjaran/Hasan Sadikin Hospital, Bandung, Indonesia \\ Email: *tantobayuaji@icloud.com, wiryawan_permadi@yahoo.com, heda_1155@yahoo.com
}

How to cite this paper: Bayuaji, H., Permadi, W. and Nataprawira, H.M.N. (2017) The Fitz Hugh-Curtis Syndrome and Hydrosalpinx: Analysis of Findings in Gynecologic Laparoscopy Procedure of Infertile Women. Open Access Library Journal, 4: e3742. https://doi.org/10.4236/oalib.1103742

Received: June 16, 2017

Accepted: July 3, 2017

Published: July 6, 2017

Copyright $\odot 2017$ by authors and Open Access Library Inc.

This work is licensed under the Creative Commons Attribution International License (CC BY 4.0).

http://creativecommons.org/licenses/by/4.0/

\begin{abstract}
Method: the study was conducted to analyze the correlation between Fitz Hugh-Curtis syndrome (FHCS) with the occurrence of hydrosalpinx, and the risk for hydrosalpinx occurrence due to FHCS. This observational retrospective study was conducted by reviewing the medical records of 315 infertile women who underwent gynecologic laparoscopy procedure from 2011 to 2016. FHCS was characterized by the presence of perihepatic adhesion between Glisson's capsule and anterior peritoneum, forming "violin string” appearance, and categorized as a mild, moderate, and severe form. The comparison of the degree of FHCS and hydrosalpinx occurrence was analyzed using $\chi^{2}$ test. The odds ratio was calculated to analyze the risk for hydrosalpinx occurrence in the presence of FHCS. The p-value $<0.05$ was considered significant. Of 315 subjects, FHCS was found in 108 subjects (34.3\%), while hydrosalpinxwas found in 107 subjects (34\%). Sixty-eight subjects (63\%) have a severe degree of FHCS. In subjects with FHCS, $64.5 \%$ had hydrosalpinx. There was a significant difference in the perihepatic adhesion degree and the occurrence of hydrosalpinx $\left(\chi^{2}=7.55 ; \mathrm{p}=0.02\right)$. There was a significant difference in hydrosalpinx occurrence between FHCS-positive and -negative group $\left(\chi^{2}=\right.$ $65.60, \mathrm{p}<0.05)$. The risk of hydrosalpinx occurrence was higher in the presence of FHCS compared with those without FHCS (OR 7.87; 95\% CI 4.64 13.33, $\mathrm{p}<0.05)$. Conclusion: the risk for hydrosalpinx was elevated in FHCS.
\end{abstract}

\section{Subject Areas \\ Gynecology \& Obstetrics}




\section{Keywords}

Fitz Hugh-Curtis Syndrome, Hydrosalpinx, Female Infertility, Tubal Pathology

\section{Introduction}

Fallopian tube pathology is an important aspect, causing $25 \%-35 \%$ cases of female infertility [1]. The most common etiology is the pelvic inflammatory disease (PID), which may lead to the occurrence of Fitz Hugh-Curtis syndrome (FHCS) [2]. FHCS is characterized by perihepatic adhesion formation between the Glisson's capsule and anterior parietal peritoneum without liver parenchymal involvement. It was believed that FHCS might occur as an ascending process from PID and correlated with some microorganism, i.e., Chlamydia trachomatis, Neisseria gonorrhoeae, and Mycobacterium tuberculosis. In the acute phase, FHCS might be manifested as right upper abdominal pain with fever, while in the chronic phase it may be symptomless [3]. The prevalence of FHCS reported from the various study was contradicting. Some studies reported that FHCS was a rare condition [4] [5] [6] [7], while in other studies the prevalence was reported from $14.6 \%$ to $16.6 \%$ [8] [9].

The most severe form of tubal damage was hydrosalpinx, the distal tubal occlusion with fluid accumulation, leading to anatomic distortion and tubal function abnormality [10] [11] [12]. It might prevent fertilization of gametes, and also may affect endometrial receptivity in in-vitro fertilization (IVF) program due to embryotoxic fluid contamination [13] [14] [15], flushing effect in the uterine cavity, bathing of the endometrial cavity with fluid, and the presence of thin layer of fluid that may impede embryo implantation [12]. The live birth rate, therefore, is compromised to $50 \%$ in the presence of hydrosalpinx [2]. Hence, several guidelines suggest hydrosalpinx should be managed before IVF program was commenced [2] [16].

With regards to the adverse effect of hydrosalpinx, the analysis of the impact of FHCS to hydrosalpinx formation becomes important especially in the high PID incidence region. However, the study on this topic is scarce. Therefore, we conducted the study to assess the risk of occurrence of hydrosalpinx in the presence of FHCS.

\section{Material and Methods}

This retrospective study was performed by reviewing the records of in female infertility patients in Assisted Reproductive Technology Unit, Hasan Sadikin Hospital Bandung, Indonesia during the 2011-2016 period. Subjects included in this study were 20 - 40 years old infertile female who underwent the laparoscopic procedure as a part of the management protocols. Subjects with previous abdominal surgery were excluded from this study. This study was approved by the Ethical Committee for Health Research, Hasan Sadikin Hospital Bandung. All patients have given their general consent before receiving management from the 
hospital.

The reviewing process of subjects' medical record was done by assessing the medical record, images, and videos obtained during surgery. FHCS was characterized by the presence of perihepatic adhesion between Glisson's capsule and anterior peritoneum, forming "violin string" appearance. The perihepatic adhesion was assessed using criteria proposed by Kobayashi et al. [9]: mild adhesion if there were less than five filmy, thin adhesion fibers between right hepatic lobe and anterior abdominal wall, moderate if more than five adhesion fibers were found in right hepatic lobe, and severe if the adhesion were found in both lobes (Figure 1). Tubal patency was assessed by chromopertubation using methylene blue solution, and confirmed by dye visualization at the fimbriae. Each fallopian tube was considered as one observation unit.

Statistical analysis was performed using IBM SPSS version 24 (IBM Analytics, Chicago, IL, USA). The analysis of the degree of FHCS and presence of hydrosalpinx was analyzed using $\chi^{2}$ test. The risk of having hydrosalpinx due to the presence of FHCS was calculated as odds ratio analysis. A p-value $<0.05$ was considered significant.

\section{Results}

Three hundred fifteen subjects were analyzed in this study. The subjects' age

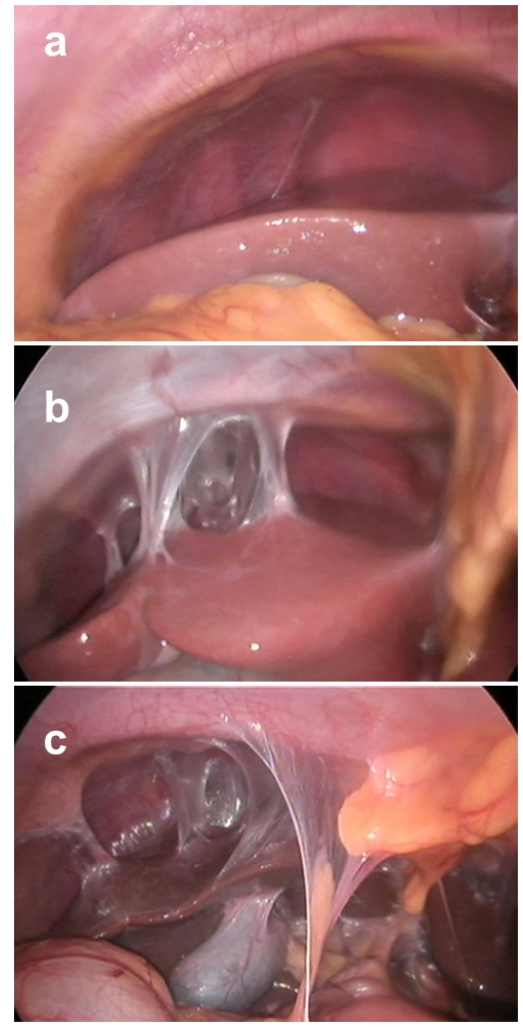

Figure 1. Classification of FHCS (a) Mild adhesion: less than five filmy, thin adhesion fibers between the right hepatic lobe and anterior abdominal wall; (b) Moderate: more than five adhesion fibers were found in the right hepatic lobe; and (c) Severe: the adhesion were found in both lobes. 
mean was 32.1 (6.5) years. All of the subjects did not complain about signs and symptoms of the acute phase of FHCS. The most common indication for laparoscopy is the management of fallopian tube disease (69.5\%) followed by management of endometrioma (14.6\%). The non-patent tube was identified in $48.4 \%$ tubes, and hydrosalpinx was found in 107 subjects (34\%). FHCS was found in 108 subjects (34.3\%), and 69 subjects among them (21.9\%) also had hydrosalpinx (Table 1). From 4 subjects with pelvic tuberculosis confirmed by histopathologic examination, all subjects of this subset had FHCS (three severe and one moderate degree) and hydrosalpinx (data not shown).

From subjects with FHCS, severe adhesion was found in $44.4 \%$ subjects with hydrosalpinx and $18.5 \%$ subjects without hydrosalpinx. Using $\chi^{2}$ test, there was a significant difference in the perihepatic adhesion degree and the occurrence of

Table 1. Characteristics of the subjects and laparoscopic findings.

\begin{tabular}{|c|c|}
\hline & $\mathrm{N}(\%)$ \\
\hline \multicolumn{2}{|l|}{ Characteristics } \\
\hline Age, mean $(S D)$ years & $32.1(6.5)$ \\
\hline \multicolumn{2}{|l|}{ Indication of laparoscopy } \\
\hline Tubal obstruction & $219(69.5)$ \\
\hline Endometrioma & $46(14.6)$ \\
\hline Uterine fibroids & $20(6.3)$ \\
\hline Ectopic pregnancy & $7(2.2)$ \\
\hline Pelvic tuberculosis & $4(1.3)$ \\
\hline Others (congenital anomalies, unexplained infertility) & $19(6)$ \\
\hline Total & $315(100)$ \\
\hline \multicolumn{2}{|l|}{ Laparoscopic findings } \\
\hline \multicolumn{2}{|l|}{ Tubal patency ${ }^{*}$} \\
\hline Patent & $325(51.6)$ \\
\hline Non-patent & $305(48.4)$ \\
\hline Total & $630(100)$ \\
\hline Fitz Hugh-Curtis syndrome & $108(34.3)$ \\
\hline \multicolumn{2}{|l|}{ Perihepatic adhesions } \\
\hline Mild & $21(19.4)$ \\
\hline Moderate & $19(17.6)$ \\
\hline Severe & $68(63)$ \\
\hline Total & $108(100)$ \\
\hline \multicolumn{2}{|l|}{ Hydrosalpinx } \\
\hline With FHCS & $69(64.5)$ \\
\hline Without FHCS & $38(35.5)$ \\
\hline Total & $107(100)$ \\
\hline
\end{tabular}

${ }^{*}$ One tube was considered as one observation unit. 
Table 2. The comparison of perihepatic adhesion degree in FHCS and hydrosalpinx occurrence.

\begin{tabular}{cccc}
\hline & Hydrosalpinx & No hydrosalpinx & $\mathrm{p}$ \\
\hline Perihepatic adhesion degree & & & \\
Mild & $8(7.4 \%)$ & $13(12 \%)$ & $\chi^{2}=7.55$ \\
Moderate & $13(12 \%)$ & $6(5.6 \%)$ & $\mathrm{p}=0.023$ \\
Severe & $48(44.4 \%)$ & $20(18.5 \%)$ & \\
\hline
\end{tabular}

Table 3. Risk analysis of hydrosalpinx occurrence due to the presence of FHCS.

\begin{tabular}{|c|c|c|c|c|c|}
\hline & & \multicolumn{2}{|c|}{$\begin{array}{l}\text { Fitz Hugh-Curtis } \\
\text { syndrome }\end{array}$} & \multirow[t]{2}{*}{$\mathrm{N}$} & \multirow{2}{*}{ Analysis } \\
\hline & & Positive & Negative & & \\
\hline \multirow{2}{*}{ Hydrosalpinx } & Positive & 69 & 38 & 107 & \multirow{3}{*}{$\begin{array}{c}\chi^{2}=65.60, \mathrm{p}<0.05 \\
\mathrm{OR}=7.87 ; 95 \% \mathrm{CI} 4.64-13.33 \\
\mathrm{p}<0.05\end{array}$} \\
\hline & Negative & 39 & 169 & 208 & \\
\hline Total & & 108 & 207 & 315 & \\
\hline
\end{tabular}

hydrosalpinx $\left(\chi^{2}=7.55 ; \mathrm{p}<0.05\right)$ (Table 2).

There was a significant difference in hydrosalpinx occurrence between FHCSpositive and -negative group, with odds-ratio 7.87 (95\% CI $4.64-13.33, \mathrm{p}<0.05)$ (Table 3).

\section{Discussion}

The most common indication for the laparoscopic procedure was fallopian tube disease evaluation and management. Furthermore, using one tube as one unit of observation, the non-patent tube was found in $48.4 \%$ observation. This was in-line with the global incidence of tubal pathology, which accounts for $25 \%-35 \%$ of female infertility problems [1]. Hence, this reveals the importance of recognizing tubal pathology as a probable cause of infertility.

We found FHCS in $34.3 \%$ of our subjects. From those, hydrosalpinx was found in 69 subjects (21.9\%). This was higher than those observed by Sharma et al. who reported $16.6 \%$ FHCS in infertile subjects, and Kobayashi et al. who reported $14.8 \%$ of the same subjects characteristics [8] [9]. The incidence of PID in the population may influence the incidence of PID, and in turn, may affect the incidence of FHCS too. However, the exact data of PID incidence in our country is lacking, leading to difficulties in the prediction of FHCS prevalence in general population.

The incidence of FHCS ranges from $4 \%-14 \%$ in women with PID [17]. Chlamydia trachomatis and Neisseria gonorrhoeae were considered the principal causative agent. The correlation between Chlamydia trachomatis infection and FHCS has been explored in several studies [18] [19]. Although the pathogenesis of FHCS due to Chlamydia trachomatis and Neisseria gonorrhoeae infection is still poorly understood, there were several probable mechanisms: the thinning of cervical mucus, and subsequent ascending transmission of the vagina to the 
uterus, fallopian tube, paracolic gutter and reached Glisson's capsule. The flow of peritoneal fluid from pelvis to subdiaphragmatic area mainly in the right area was considered significant. The bacteria may spread via the direct extension from peritoneal fluid from the pelvis through the paracolic gutter [22] [21]. In-line with this concept, we observed the severe-degree perihepatic adhesion was the most common finding in FHCS.

In this study, hydrosalpinx was found in 107 subjects (34\%), and mostly found in severe perihepatic adhesion. Hydrosalpinx might be found in $10 \%-35 \%$ infertile couple with fallopian tube pathology [14] [22]. It was the most severe form of tubal pathology, leading to accumulation of intraluminal fluid that may interfere with fertility treatment outcomes. Strandell et al. found that hydrosalpinx may compromise embryo implantation in the IVF program due to mechanical flushing effects of hydrosalpinx fluid, and also toxic reactions in the uterine cavity [13]. The management of hydrosalpinx before IVF is now recommended as stated in several reviews [12] [14]. This may be done by salpingectomy, proximal tubal occlusion, hysteroscopic insertion of devices, sclerotherapy, and ultrasound-guided aspiration [14].

The risk for hydrosalpinx occurrence was 7.87 times higher in subjects with FHCS compared with those without FHCS. This might emphasize the importance of PID sequelae that might lead to tubal pathology. However, all of the subjects did not complain about the acute signs and symptoms of FHCS, making the prompt diagnosis and treatment difficult.

We found four subjects FHCS and hydrosalpinx due to tuberculous salpingitis. Three subjects had severe degree perihepatic adhesion. Sharma et al. found a high prevalence of FHCS in subjects with tuberculosis (48.7\%) [23]. Furthermore, they also found the correlation between abdominal and pelvic adhesion with the severity of FHCS. They suggested considering performing tuberculosis testing to patients with infertility or chronic pelvic pain who had FHCS in high prevalence area. This was aimed to prevent further damage to the abdominal and pelvic organ. Since tuberculosis still becomes an important health issue in developed countries, we recommend further research on this topic.

There are some limitations of this study. First, the etiological factor was not assessed in this study. The detection of both Chlamydia trachomatis and Neisseria gonorrhoeae as the main etiology for FHCS was not a routine procedure in our hospital, therefore the data regarding possible etiology was lacking. Second, the detection of acute phase characteristics was not routinely done. The acute phase of FHCS may not be specific and may easily be missed. Moreover, the infertile patients who came to our hospital seldom complain about the acute characteristics that may lead to FHCS.

\section{Conclusion}

Fitz Hugh-Curtis syndrome was found in $34.4 \%$ of our study subjects. There was a significant difference between the severity of perihepatic adhesion in FHCS and hydrosalpinx occurrence. The risk for hydrosalpinx occurrence in the pres- 
ence of FHCS was 7.87.

\section{Acknowledgements}

H.B. would like to thank BayuIndrayana Irsjad, MD for the assistance during preparation of the manuscript.

\section{References}

[1] Practice Committee of the American Society for Reproductive Medicine (2015) Role of Tubal Surgery in the Era of Assisted Reproductive Technology: A Committee Opinion. Fertility and Sterility, 103, e37-e43. https://doi.org/10.1016/j.fertnstert.2015.03.032

[2] Practice Committee of American Society for Reproductive Medicine in Collaboration with Society of Reproductive Surgeons (2008) Salpingectomy for Hydrosalpinx Prior to in Vitro Fertilization. Fertility and Sterility, 90, S66-S68.

[3] Bolaji, I.I. and Shirley, K.Y. (2015) An Odyssey through Fitz-Hugh Curtis Syndrome. Journal of Reproduction and Contraception, 26, 173-186.

[4] Muschart, X. (2015) A Case Report with Fitz-Hugh-Curtis Syndrome, What Does It Mean? Acta Clinica Belgica, 70, 357-358. https://doi.org/10.1080/17843286.2015.1131964

[5] Keane, J.A., McKimm, R.J. and David, C.M. (1982) Perihepatitis Associated with Pelvic Infection: The Fitz-Hugh-Curtis Syndrome. The New Zealand Medical Journal, 95, 725-728.

[6] Cusimano, A., Abdelghany, A.M. and Donadini, A. (2016) Chronic Intermittent Abdominal Pain in Young Woman with Intestinal Malrotation, Fitz-Hugh-Curtis Syndrome and Appendiceal Neuroendocrine Tumor: A Rare Case Report and Literature Review. BMC Women's Health, 16, 3. https://doi.org/10.1186/s12905-015-0274-2

[7] MacLean, A.B. (2008) Fitz-Hugh-Curtis Syndrome. Journal of Obstetrics and Gynaecology, 28, 259-260. https://doi.org/10.1080/01443610802042993

[8] Sharma, J.B., Malhotra, M. and Arora, R. (2002) Incidential Fitz-Hugh-Curtis Syndrome at Laparoscopy for Benign Gynecologic Conditions. International Journal of Gynecology \& Obstetrics, 79, 237-240. https://doi.org/10.1016/S0020-7292(02)00231-X

[9] Kobayashi, Y., Takeuchi, H., Kitade, M., Kikuchi, I., Sato, Y. and Kinoshita, K. (2006) Pathological Study of Fitz-Hugh-Curtis Syndrome Evaluated from Fallopian Tube Damage. Journal of Obstetrics and Gynaecology Research, 32, 280-285. https://doi.org/10.1111/j.1447-0756.2006.00399.x

[10] Gomel, V. and Taylor, E. (2008) Reconstructive Tubal Surgery. In: Rock, J.A. and Jones, H.W., Eds., Te Linde's Operative Gynecology, Lippincott Wiliams \& Wilkins, Philadelphia, 403-437.

[11] Hafner, L.M. (2015) Pathogenesis of Fallopian Tube Damage Caused by Chlamydia Trachomatis Infections. Contraception, 92, 108-115.

[12] Johnson, N., van Voorst, S., Sowter, M.C., Strandell, A. and Mol, B.W. (2010) Surgical Treatment for Tubal Disease in Women Due to Undergo in Vitro Fertilisation. The Cochrane Database of Systematic Reviews, No. 1, CD002125.

[13] Strandell, A. (2000) The Influence of Hydrosalpinx on IVF and Embryo Transfer: A Review. Human Reproduction Update, 6, 387-395.

https://doi.org/10.1093/humupd/6.4.387 
[14] D’Arpe, S., Franceschetti, S., Caccetta, J., Pietrangeli, D., Muzii, L. and Panici, P.B. (2015) Management of Hydrosalpinx before IVF: A Literature Review. Journal of Obstetrics and Gynaecology, 35, 547-550. https://doi.org/10.3109/01443615.2014.985768

[15] Ozmen, B., Diedrich, K. and Al-Hasani, S. (2007) Hydrosalpinx and IVF: Assessment of Treatments Implemented Prior to IVF. Reproductive BioMedicine Online, 14, 235-241.

[16] Chua, S.J., Akande, V.A. and Mol, B.W. (2017) Surgery for Tubal Infertility. The Cochrane Database of Systematic Reviews, 1, CD006415. https://doi.org/10.1002/14651858.cd006415.pub3

[17] Peter, N.G., Clark, L.R. and Jaeger, J.R. (2004) Fitz-Hugh-Curtis Syndrome: A Diagnosis to Consider in Women with Right Upper Quadrant Pain. Cleveland Clinic Journal of Medicine, 71, 233-239. https://doi.org/10.3949/ccjm.71.3.233

[18] Wang, S.P., Eschenbach, D.A., Holmes, K.K., Wager, G. and Grayston, J.T. (1980) Chlamydia Trachomatis Infection in Fitz-Hugh-Curtis Syndrome. American Journal of Obstetrics \& Gynecology, 138, 1034-1038.

[19] Perquin, D.A., Beersma, M.F., de Craen, A.J. and Helmerhorst, F.M. (2007) The Value of Chlamydia Trachomatis-Specific IgG Antibody Testing and Hysterosalpingography for Predicting Tubal Pathology and Occurrence of Pregnancy. Fertility and Sterility, 88, 224-226.

[20] Onoh, R.C., Mgbafuru, C.C., Onubuogu, S.E. and Ugwuoke, I. (2016) Fitz-HughCurtis Syndrome: An Incidental Diagnostic Finding in an Infertility Workup. Nigerian Journal of Clinical Practice, 19, 834-836. https://doi.org/10.4103/1119-3077.181357

[21] Ekabe, C.J., Kehbila, J., Njim, T., Kadia, B.M., Tendonge, C.N. and Monekosso, G.L. (2017) Chlamydia Trachomatis-Induced Fitz-Hugh-Curtis Syndrome: A Case Report. BMC Research Notes, 10, 10. https://doi.org/10.1186/s13104-016-2357-z

[22] Audebert, A., Pouly, J.L., Bonifacie, B. and Yazbeck, C. (2014) Laparoscopic Surgery for Distal Tubal Occlusions: Lessons Learned from a Historical Series of 434 Cases. Fertility and Sterility, 102, 1203-1208.

[23] Sharma, J.B., Roy, K.K., Gupta, N., Jain, S.K., Malhotra, N. and Mittal, S. (2007) High Prevalence of Fitz-Hugh-Curtis Syndrome in Genital Tuberculosis. International Journal of Gynecology \& Obstetrics, 99, 62-63.

\section{List of Abbreviations}

FHCS: Fitz Hugh Curtis Syndrome

PID: Pelvic Inflammatory Disease

IVF: In Vitro Fertilization 
Submit or recommend next manuscript to OALib Journal and we will provide best service for you:

- Publication frequency: Monthly

- 9 subject areas of science, technology and medicine

- Fair and rigorous peer-review system

- Fast publication process

- Article promotion in various social networking sites (LinkedIn, Facebook, Twitter, etc.)

- Maximum dissemination of your research work

Submit Your Paper Online: Click Here to Submit

Or Contact service@oalib.com 